\title{
A Question of Time: Sociotemporality in Academic Libraries
}

\section{Lora L. Lennertz and Phillip J. Jones}

The clock and calendar regulate many library activities, but the seasonal and temporal dimensions of libraries are largely unexplored. Intrigued by observations of colleagues' temporal attitudes and behavior, the authors drew on the work of sociologist Eviatar Zerubavel to investigate the perceptions of time, schedules, and urgency among professional library personnel. The data showed almost no statistically significant relationships between demographic categories and the employee's approach to time; however, multiple significant relationships existed between the latter and the employee's department. These findings can help academic librarians understandand bridge-differences among themselves to build more vigorous organizations.

\section{Introduction}

Since the Industrial Revolution, time has been central to measurements of productivity-and to life in general. Days, weeks, months, seasons, and years are omnipresent units around which modern individuals plan their lives, both inside and outside the workplace. At first glance, time appears strictly empirically defined: one day roughly corresponds to one axial rotation of the earth, one year roughly corresponds to one solar rotation of the earth, and one season represents specific movement of the earth relative to the equator and the two equinoxes. The omnipresence and empirical dimensions of time, however, can obscure how time is more complex than an empirical standard: time is also socially constructed. Seconds, minutes, hours, weeks, and months are random inventions. There is no reason to divide a day into 24 hours, any more than there is a reason to start either the workday at 8:00 a.m. or the workweek on Monday, the leading custom in the United States and many other countries. ${ }^{1}$

During the past five decades, many social scientists and historians have studied the human and social dimensions of time, including in the workplace. ${ }^{2}$ At a basic level, their scholarship indicates that individuals experience time differently; at a higher level, this research explores what this temporal diversity means for organizations. To date, the inquiry into time has not made inroads into the academic library. It is time to address this gap.

This article grew out of conversations between the authors-namely, discussions of their perceptions that their fellow academic librarians had divergent approaches to time, schedules, seasonality, and even urgency. In their roles as managers, the authors noted situations in which

\footnotetext{
${ }^{*}$ Lora L. Lennertz is Data Services Librarian at the University of Arkansas Libraries; email: lennertz@uark.edu. Phillip J. Jones is Associate Librarian and Head of Fine Arts Library at the University of Arkansas Libraries; email: pjj01@uark.edu. @2020 Lora L. Lennertz and Phillip J. Jones, Attribution-NonCommercial (https://creativecommons.org/licenses/by-nc/4.0/) CC BY-NC.
} 
other managers assigned work that conflicted with time-sensitive duties in other work areas. Examples included setting deadlines for monographic orders and other activities during the peak season for library instruction and scheduling important meetings when numbers of professional staff were at a conference or otherwise committed, such as at the beginning of an academic term. The varying approaches to time also affected interactions among personnel and showed disparity. For example, one colleague, now retired, had grumbled how a search committee meeting infringed on her coffee break.

The authors' discussions prompted a survey of colleagues at peer institutions and the subsequent report and analysis below. This research is an initial inquiry and ideally will encourage other studies into the social dimensions of time-to quote the sociologist Eviatar Zerubavel, the sociotemporal order ${ }^{3}$ - that pervade academic libraries. In this article, the authors hypothesize that library professionals have differing sociotemporal viewpoints within the workplace, in particular with regard to management of time, deadlines, and the expectations and demands of others. The intent of the following research is to bring to light the less-explored dimensions of time within the academic library so that decision makers better identify potential stressors within the work environment and address them accordingly through more careful assignment of specific tasks and goals and examination of organizational structures, with sociotemporal concerns in mind. By raising consciousness of these matters in this initial study, the authors hope to introduce a line of inquiry to be replicated in other research and to promote more self-aware and efficient libraries. These initial results suggest a curious finding in a field that extols teams and endlessly dissects demographic differences: the predominant role of the library department in organizational culture.

\section{Literature Review}

Scholars have pondered the meaning and experiential dimensions of time in a body of work that stretches back to Augustine. ${ }^{4}$ Many academics in the last century agreed that a shift had occurred that separated premodern from modern temporalities. ${ }^{5}$ The historian E.P. Thompson argued forcefully in a 1967 article that the Industrial Revolution was this watershed: the irregular labor patterns and imprecise temporality of the agrarian medieval and early modern eras gave way to a rigid time-discipline that governed both the personal and work lives of individuals in the world's more developed economies. ${ }^{6}$ As a result of its hypermeasurement, time had become a commodity, something to be "spent" wisely. ${ }^{7}$ Thompson offered several reasons for this societal transformation, but the proliferation of reliable clocks and watches was a core element. ${ }^{8}$

Thompson's monumental work prompted debates within and beyond the field of history. ${ }^{9}$ Published almost 40 years ago, Eviatar Zerubavel's groundbreaking sociological analysis of one university hospital in the United States, Patterns of Time in Hospital Life, applied a temporal lens to parallel professions within this institution, a project most relevant to an investigation of temporality in the academic library. As noted in his introduction, time is omnipresent but often overlooked by sociologists; he proposed "to deal with temporality as a sociological topic in its own right." 10 Zerubavel examined the calendars on which the hospital's activities were based: daily and weekly schedules, the various shifts and rotations, and the staggered nature of multiple cycles (such as the "year" of the junior residents). He then explored the ways in which the categories of employees (doctors, nurses, interns, residents, and nonmedical staff) experienced time differently. As an example, most nurses worked shifts that clearly demarcated 
"on" and "off" duty, whereas the boundary between doctors' personal and work schedules was murky. To define his research, Zerubavel used the term "sociotemporal order,"11 making an analogy to the "physiotemporal" and "bio temporal" orders that typify organisms. Zerubavel extended his analysis beyond the workplace in a subsequent book in which he covered the Western and other calendars, temporal regularity, and the binary distinctions of sacred/profane time and private/public time. ${ }^{12}$

The concept of private and public time has been the topic for additional research. Indubitably one's personal and professional lives can conflict with each other. The sociologist Christena Nippert-Eng, whom Zerubavel advised as his graduate student, ably explored how employees navigate the boundaries between their domestic and professional lives in Home and Work: Negotiating Boundaries through Everyday Life, and it is clear that individuals with children and other caregiving responsibilities, particularly women, face special obstacles at work. ${ }^{13}$ Christine Everingham examined these challenges in an insightful critique of gender equity and workplace flexibility, arguing that discourses of workplace flexibility and derivative policies erode a separation of "home" and "work" that benefits working mothers, who confront rigid and highly gendered demands in their private lives. ${ }^{14}$

As these two studies looked at time on a personal level, other social scientists have contributed to a body of work on the diverse temporal aspects of organizations. The medical field has continued to attract this type of analysis. Using a mixture of qualitative and quantitative measures, Quan et al. probed communication between nurses and doctors to identify gaps between their definitions of medical urgency - specifically, the nurse's summoning a doctor rather than sending a message into a queue. ${ }^{15}$ The researchers uncovered some divergence of opinions by the two groups: nurses tended to identify time-sensitive cases as urgent when doctors reserved the label strictly for clinical urgency. ${ }^{16}$ They also found a nurse's change in shift could be a factor in the nurse's definition of urgency, ${ }^{17}$ which reinforced Zerubavel's point that, unlike doctors, nurses adhered strictly to shifts.

Research in organizational time outside medicine has often looked at the effects on work groups, including from the view of the supervisor or manager. Hassard argued that adaption to the temporal rhythms of organizations, including the workplace, is a prime element of socialization. ${ }^{18}$ Organizations must address the scarcity of time to be effective. Although Hassard alluded to "conflicts over activities," 19 he did not flesh out the temporal dimensions of these conflicts or the discordant orientations of work groups. Albert argued that contemporary "network society" has led to a monolithic time that has undermined temporal diversity. ${ }^{20} \mathrm{It}$ is likely within the subsequent work culture that managers' and subordinate employees' approaches to time will collide, as do the flexible and rigid schedules of contemporary society. The capitalist economy desires nimble employees ready to respond to immediate demands in a global society; the "social and personal needs" of employees affect their focus on their jobs, creating a dynamic tension. ${ }^{21}$ Waller et al. proposed four categories of workers vis-à-vis two binary temporal characteristics (low/high time urgency and present/future perspective) and discussed the dynamics that emerge within teams when their members represent multiple quadrants, particularly the effects on employees' perception of deadlines. ${ }^{22}$ In their study of time variation across work groups, and with a focus on communication, Ballard and Seibold surveyed 337 employees at a cable subcontractor with offices in three areas of the United States. They found that the work groups differed in significant ways with regard to time and that "their varied communication demands and patterns were a factor in these differences." 23 
Mohammed and Nadkarni found in a medium-sized Indian company that effective temporal leadership by managers mitigated some, but not all, challenges arising from employees' divergent approaches to the urgency and pacing of their tasks. ${ }^{24}$ In a subsequent article, Mohammed and Harrison proposed for future research a series of propositions regarding the performance of teams and variation among their members in urgency, temporal perspectives, polychronicity, and pacing. ${ }^{25}$ In Schriber and Gutek, importance was given to how time periods are developed and scheduled. "For organizations, the effective scheduling, coordination, and synchronization of people and tasks through time is a key to survival, growth, and profitability." ${ }^{26}$ For the individual within the organization, understanding temporal norms such as deadlines and schedules can determine a worker's success or failure. Halbesleben et al. discussed time as it is reflected in organizational creativity, stating that "awareness of temporal complexity dimensions has significant impact on the leader competency set that is critical to lead people effectively in innovation-focused projects." ${ }^{27}$

Scholars with expertise in temporal analysis have investigated business and medicine more frequently; however, academe is not absent from the research, which has looked primarily at perceptions of time and urgency among faculty, staff, and students. Although not an article on the variety of employees' temporal experiences per se, Kyvik's longitudinal study of faculty at the four major Norwegian universities questioned the reliability of employees' perceptions of their obligations and schedules. ${ }^{28}$ Data drawn from surveys administered in 1982, 1992, 2001, and 2008 suggested that, although faculty believed that their jobs had become more demanding over time, they were working slightly fewer hours. ${ }^{29}$ Konrad and Kline compared urgency across seven categories among faculty/students and supervisors/workers in both a factory and a university. To their surprise, they found greater urgency in the university than the factory and that supervisors showed no greater urgency than their employees. ${ }^{30}$ Their study referred to the "possible existence of various subcultures in organization" but did not explore these subcultures. ${ }^{31}$ Mizrachi and Bates's ethnographic inquiry of a personal space, the dormitory of a major research university, probed the myriad of approaches that undergraduates took to seek and use information. It included aspects of urgency and time management, as well as the institutional and course calendars to which students adapted. The authors used primarily qualitative methods and did not seek statistically significant patterns of use among categories of students. ${ }^{32}$ With a sample of 131 college students, Meyers and Sewell studied the temporal attitudes of young adults in five specific categories: time consciousness, time management, time indifference, time learning, and time experience. ${ }^{33}$ They found a significant difference between the genders for time indifference, a marginally significant difference for time learning, and no significant differences for the other three. ${ }^{34}$

The literature on librarianship has examined time, particularly in the areas of time management and urgency, but has yet to develop a framework approximating Zerubavel's. In an article that compared temporal elements of library work with another field, Greenberg concluded that employees predisposed to high time urgency (TU)-emergency room nurses in his sample-performed better in a highly urgent environment and less well in a less urgent one, whereas employees predisposed to low TU-rural public librarians in his sample-performed better in a less urgent setting and less well in a highly urgent one. Although he used persons from each profession to validate his categorization of each as high time-urgent or low time-urgent, he did not address variations within each field on his scale or the variety of jobs within either field. ${ }^{35}$ Ifijeh discussed the importance of time management in academic libraries, 
but his practical approaches to organizational efficiency did not explore differences among individuals or the socially constructed dimensions of time. ${ }^{36}$ Anderson proposed a matrix of spatial and temporal orientations to library work with two binary axes: global/local and longterm/short-term. ${ }^{37}$ He argued that each library and staff member occupied a spot on this grid and that when "unsustainable friction" arose between the employer and an employee with a contrasting proclivity, the ethical mandate was for the librarian "to look for other work." 38 Miller and Keenan investigated time management in technical services at the libraries of the universities of Montana and Nevada, Reno. The authors analyzed employees' categorization of their activities as a foundation for improving operations and increasing efficiency. Miller and Keenan did not consider the sociotemporal dimensions of these departments. ${ }^{39}$

\section{Methodology}

The authors constructed a survey to determine if librarians and other professionals within libraries were subject to different influences and perceptions of time. Although the authors examined other survey-based research articles for inspiration, the questions were the authors'. Two consortia in the United States were chosen as the population from which to poll personnel: the Greater Western Library Alliance (GWLA), a body of 35 academic libraries in 2015, and the Southeastern Conference (SEC). The members of the consortia had similar missions and close affinities to the authors' employer, the University of Arkansas, which belonged to both. Arguably these are regional consortia, but their members vary in size and span four time zones. Although quantitative studies in library science typically poll only librarians, the authors chose to include nonlibrarian professional personnel, partially in response to James Neal's recognition of "feral professionals" 40 - library employees who lack the accredited master's degree in library and information science but hold jobs classified as professional, such as accountants, human resource managers, and copyright experts - and also in acknowledgment of the changing nature of professionalism within libraries. These employees are also likely to share with librarians exempt status under the Fair Labor Standards Act and therefore can be required to work overtime without additional compensation, suggesting a kinship in the sociotemporal realm.

A draft of the survey was distributed to local colleagues for feedback, after which minor changes were made. The University of Arkansas Institutional Review Board approved the final version, which consisted of 60 questions. The initial portion elicited demographic information, such as gender, age, years of professional library experience-and the respondent's department. This last category was included because the authors hypothesized that, paired with other variables, some statistical significance would emerge. The authors recognized that "departments" might not be consistently defined across libraries. However, as a label in a study of perceptions, "department" remains a credible category of analysis, as does the common demographic variable of gender, which is no longer binary, and on which claims of statistical significance continue to be based. For this particular study, the respondents themselves chose the department in which they worked or "were most closely associated" and selected overwhelmingly two departments when asked to identify which department "was most governed by deadlines."

The remaining questions on the survey related to temporal engagement, such as seasonality of work, workday regularity, urgency, and the impact of time on different units within the library. The survey included binary questions and scales of varying lengths. The complete survey, which was loaded into Qualtrics for distribution, may be found in the appendix. 
Having been told of the project, the dean of libraries at the University of Arkansas sent a message to her fellow deans and directors of GWLA, requesting their support for the forthcoming survey. Because of the difficulty of correctly identifying potential respondents across 46 institutions, the authors sent an invitation to the chief administrator (dean/director) of each of the academic libraries in May 2015, requesting that the administrator both participate and forward the invitation to librarians and other professional personnel. Each invitation included a unique URL, which allowed the authors to track participation by institution. The authors sent a second request to participate after approximately one month to the administrative offices of academic libraries that had not completed a survey. Both the message from the authors' dean to other administrators and the funneling of the survey through deans and directors likely increased the proportion of responses from administrators-and potentially skewed the results in terms of seniority, gender, and age.

By the close of the survey in July 2015, the authors had received 363 responses. One response had no data and was eliminated. Surveys were then reviewed to determine whether nonprofessional employees had responded, which might skew the results. While there was no direct question that addressed this issue, the authors determined that responding employees who had less than a bachelor's degree or had a bachelor's degree with a salary below $\$ 39,999.00$ were most likely not professional staff. This analysis resulted in an additional 37 deleted responses. Because the survey did not indicate part-time or full-time status, it is possible that several responses from part-time professionals were excluded. The removal of the 38 responses did not "eliminate" any academic library; each library that contributed one or more unusable responses submitted at least one usable one. After these deletions, 325 usable responses remained. As the authors began to examine their data for significance, the limitations of Qualtrics software became apparent and the data were moved for further analysis into SPSS. Because the data did not follow a standard distribution, the authors used the KruskalWallis test for cross-tabulations of independent and dependent variables, except in cases of binary variables, in which Fisher's exact test was used.

Several factors contributed to the difficulty of estimating the response rate. Only 23 of the 46 academic libraries responded; and, of these 23, five sent only one response, presumably from the chief administrator. It is likely that the administrator at multiple academic libraries chose not to forward the URL or failed to read the instructions. The authors computed numbers of librarians and professional staff at the 46 libraries from a variety of sources, including the ARL Annual Salary Survey and the American Library Directory. Although it is impossible to know how many the survey reached, the authors identified the population of librarians and professional staff at the 46 academic libraries at approximately 2,620. With this figure, the survey participation rate was 12.4 percent-although the organizational representation was 50.0 percent. If one considers the lopsided participation in the survey and computes the response rate based solely on the 23 responding academic libraries, which employed approximately 1,360 librarians and professional staff, the rate rises to 23.9 percent.

\section{Results}

The authors determined that the general demographic data in their results are similar to other data found in the professional literature and other statistical sources. However, aspects of the respondent population, such as the presence of nonlibrarian professionals and the preponderance of administrators, preclude the authors from claiming that their data are generalizable to all academic libraries. 
Of the 323 respondents who identified their gender, 242 (74.9\%) were female while 81 (25.1\%) were male, with two nonresponses. This percentage falls between national data on gender of "higher education credentialed librarians," which show a higher percentage of men, and national data on gender of the broader professional grouping of "credentialed librarians," which show a lower percentage. In 2000, the American Community Survey reported that men comprised 30.1 percent of librarians in higher education. ${ }^{41}$ In 2009-2010, the American Community Survey reported that men were 17.2 percent of all librarians. ${ }^{42}$ Other sources indicate similar data, with men approximately 15 to 20 percent of the profession as a whole. ${ }^{43}$ Because this survey included nonlibrarian professional staff and a high number of administrators, exact comparisons with national data are impossible, but the proportion of women and men in this study is close to what is found in other sources.

Of those surveyed, 320 identified the number of years that they had worked as a professional in libraries, according to the categories in the table below, with the sample skewing to fewer years of professional experience. It is interesting that there was a noticeably lower number of midcareer professionals within the results, although comparable dips have appeared in recent studies. ${ }^{44}$

The distribution of the reported ages of the respondents lacked the noticeable dip of years of professional service but was compatible with the known demographic of a graying profession.

The survey allowed the participants to select "other" for departmental affiliation and provide a clarifying textual response, in lieu of selecting a specific department. Among the 325 usable responses, 16 "others" were recorded, many with highly descriptive accompanying text that clearly indicated a department that had been a potential response. As the authors reviewed the descriptions, they decided that they could reassign
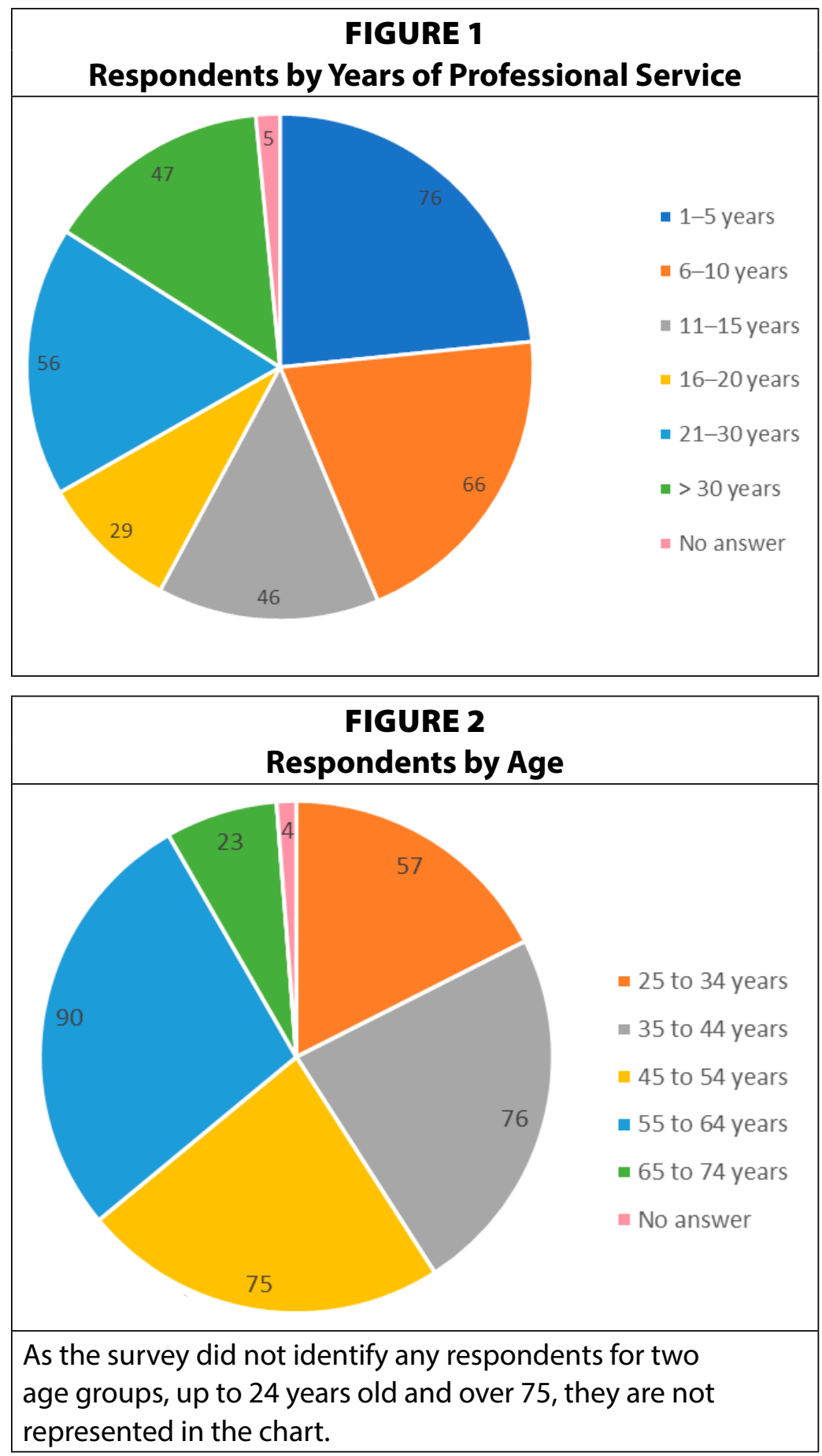
each "other" to a specific department with confidence and without loss of integrity to the data. The largest departments represented were administration $(43,13.4 \%)$ and public services $(43,13.4 \%)$, followed by reference $(42,13.1 \%)$ and special collections or archives $(34,11.0 \%)$. As mentioned above, the large number of administrators in the results may be a result of the method in which the survey was distributed and publicized.

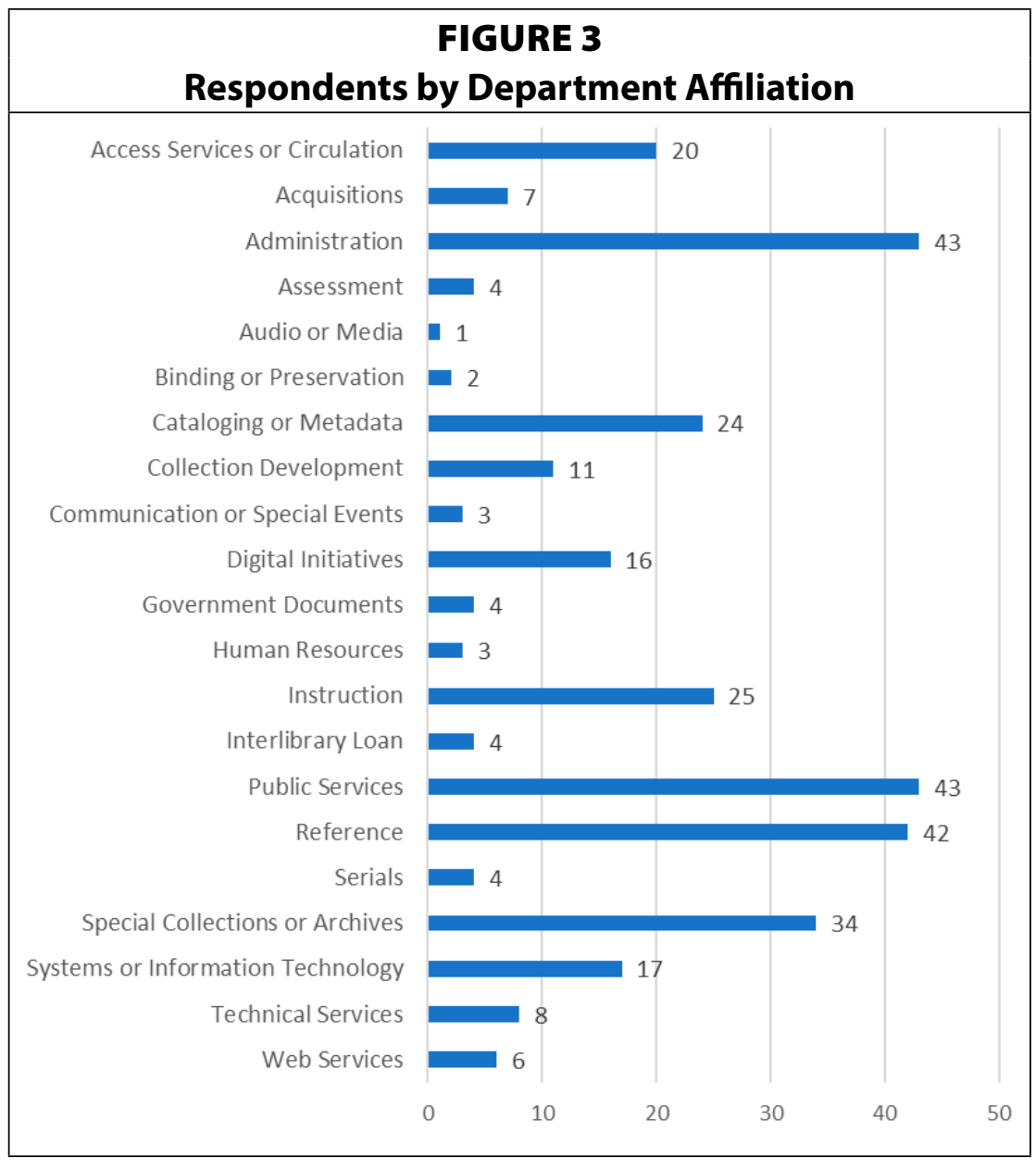

In addition to investigating raw data, the study focused on identifying the demographic factors that most affected an individual's perception of time in the library workplace. To that end, cross-tabulations of demographic information were made with the additional questions, which were tested for significance using the Kruskal-Wallis test or, when appropriate, a Fisher's exact test. For all these tests, a statistical significance was set to a level of $p$ $=.05$. If a combination showed a value of significance less than .05 , the demographic element did affect the responses to the question. If no significance was found, that particular demographic was not a factor in the responses. The authors were able to discern that many demographic areas were not significant. Gender, age, salary, and solitary householder status were not consequential to this study. The department in which a person works is the most significant factor in determining perception of time and, to a much lesser extent, the years worked in a professional library position.

An initial hypothesis of the authors was that a seasonal impact on library work exists. It was also presumed that "library" seasons, if they exist, vary by department. Of those surveyed, 72.0 percent believed that their work was seasonal (Q18 of the survey). A smaller number, 59.5 percent of the respondents, frequently were conscious of the calendar, while only 6.9 percent were not at all conscious of the academic calendar (Q15). A near-majority of respondents felt that August or September (154 total) was the most stressful month of the year and indicated in a follow-up question that the beginning of the semester, the arrival of students, the start of a new year, and classes and sessions were the primary identifiers of stressful months. January, May, and October (72 total) formed the second tier of choices for the most stressful month (Q16).

The department in which the respondents worked was a significant factor in whether the academic calendar impacted work. (The text below parenthetically indicates the distance 
from the mean followed by the number of respondents, unless otherwise noted.) Overall, library employees were somewhat conscious of the academic calendar as a factor in their work $(\mathrm{Q} 15$, mean $=2.53,321$ responses, $p=.000)$. Employees in reference $(+.23,42)$, access services or circulation $(+.22,20)$, and serials $(+.22,4)$ indicated the greatest consciousness of the academic calendar. Those least aware of the calendar were in cataloging or metadata $(-.65,24)$ and digital initiatives $(-.54,16)$. While 232 of the 321 respondents indicated that work had a seasonal aspect to it $(\mathrm{Q} 18$, mean $=1.28,321)$, departmental affiliation as a factor again showed statistical significance $(p=.000)$.

Professional employees reported significant differences by departmental affiliation for the degree by which other work units impacted their duties. In particular, library professionals identified differences by departments to the questions of the effect on their deadlines by the following entities (Q13) (see table 1).

\section{TABLE 1}

Question 13: My work duties are affected by...

\begin{tabular}{|l|c|c|l|l|}
\hline & $\boldsymbol{P}$ Value & Mean & Most Agreement & Least Agreement \\
\hline $\begin{array}{l}\text { Deadlines by the library } \\
\text { administration }\end{array}$ & .001 & 2.33 & $\begin{array}{l}\text { Human Resources } \\
+.67,3\end{array}$ & $\begin{array}{l}\text { Cataloging } \\
-.33,24\end{array}$ \\
\hline $\begin{array}{l}\text { Expectations of other } \\
\text { departments within the } \\
\text { library }\end{array}$ & .005 & 2.19 & $\begin{array}{l}\text { Binding and Preservation } \\
+.81,2 \\
\text { Human Resources } \\
+.81,3\end{array}$ & $\begin{array}{l}\text { Special Collections } \\
-.31,34\end{array}$ \\
\hline $\begin{array}{l}\text { Expectations of student and } \\
\text { faculty clientele }\end{array}$ & .000 & 2.39 & $\begin{array}{l}\text { Interlibrary Loan } \\
+.61,4\end{array}$ & $\begin{array}{l}\text { Assessment } \\
-.20,4\end{array}$ \\
\hline The campus calendar & .000 & 2.15 & $\begin{array}{l}\text { Interlibrary Loan } \\
+.91,4\end{array}$ & $\begin{array}{l}\text { Cataloging } \\
-.57,24\end{array}$ \\
\hline $\begin{array}{l}\text { External vendors and } \\
\text { businesses }\end{array}$ & .000 & 1.59 & $\begin{array}{l}\text { Acquisitions } \\
+1.12,7\end{array}$ & $\begin{array}{l}\text { Binding and Preservation } \\
-.59,2\end{array}$ \\
\hline Other Entities & .005 & 1.64 & $\begin{array}{l}\text { Human Resources } \\
+.69,3\end{array}$ & $\begin{array}{l}\text { AV } \\
-.64,1 \\
\text { Binding and Preservation } \\
-.64,2\end{array}$ \\
\hline
\end{tabular}

In contrast, there were no statistically significant differences found by departments regarding a person's own deadlines and the deadlines determined by the supervisor or internal departmental members.

The authors had witnessed varying expectations for a regular schedule among their colleagues and wished to test this observation. Several questions that related to scheduling were asked. While 149 of 325 respondents agreed or strongly agreed that they prefer a definite schedule (Q19b), no statistically significant differences were found across departments. Respondents were more likely to change their schedules to accommodate library users than for their library colleagues (Q19d, Q19a). Respondents also generally preferred to eat lunch at the same time of the day $(\mathrm{Q} 19 \mathrm{e}$, mean $=3.13,325)$. The majority $(175$ of 320) agreed or strongly agreed that they avoid working on weekends (Q19h). Departmental differences were not a factor in this response, but the number of years worked at the library was a factor (mean $=3.4,320 ; p=.015$ ). Persons 
who had worked 1 to 5 years $(+.4,76)$ in libraries more often avoided working on weekends than did other groups. Employees with 21 to 30 years $(-.33,56)$ were less likely to agree than the other groups. Two other areas of regular scheduling identified a departmental bias. While most individuals were neutral or were in agreement (247 of 325) with the statement that they arrive and leave at the same time each day (mean $=3.57)$, personnel in government documents $(+.93,4)$, interlibrary loan $(+.68,4)$, acquisitions $(+.86,7)$, communications or special events $(+.76,3)$, and assessment $(+.67,4)$ were more likely to do so. Web services $(-.74,6)$ and instruction $(-.49,25)$ were less likely to agree. Although most respondents indicated that they did not work regularly from home (mean $=2.02,321, p=.002)$, persons in instruction were most likely to do so $(+.86,25)$.

In an era of attention to work/life balance, the authors were interested in determining the degree to which professionals were able to separate work time from personal time. Departmental affiliation proved to be a statistically significant factor in scheduling vacations (Q13, $p=.01)$ and staying connected to the office during vacations (Q14, $p=.003)$. While 73.8 percent responded that scheduling vacations was occasionally (170 of 325) or frequently (70 of 325) impacted by work responsibilities (mean $=1.95,321$ responses), interlibrary loan $(+.55,4)$ and acquisitions $(+.48,7)$ indicated the highest responses. In all, 72.3 percent indicated that they occasionally or frequently were required to be "connected" while on vacation (mean $=1.90,325)$. Personnel in administration and acquisitions rated connection most highly (administration, $+.50,43$; acquisitions $+.24,7)$. Also, a majority indicated that they maintain some availability to the library when not at work (mean $=3.47,320)$. Members of the administration $(+.67,43)$, human resources $(+.86,3)$, and communication or special events $(+.86,3)$ scored the highest. Binding or preservation $(-.97,2)$, cataloging or metadata $(-.55,24)$, and serials personnel $(-.72$, 4 ) were least likely to remain available when out of office. Out of the sample (mean $=2.72,325)$, administration $(+.75,43)$ and human resources $(+1.28,3)$ indicated the greatest likelihood of taking work home (Q19c), as compared to serials $(-.97,4)$ and interlibrary loan $(-.97,4)$. The statement "attending campus activities outside of my regular schedule is an important aspect of membership in academe" (Q26a) was intended to identify the likelihood of a respondent's attendance at such occasions, although some who were committed in principle might not follow through in practice. Overall, the response to this statement was more positive, with 219 of 325 of the respondents agreeing (mean $=3.72$ ). Professionals in human resources $(+.95,3)$ and reference $(+.38,42)$ responded most positively to this statement.

Urgency and pacing of tasks, as well as their unpredictability, can be of concern in libraries and factors of stress. The authors posited that workday rhythms would vary across departments. Library professionals responded to three related statements on a scale of 0 (never) to 10 (very frequently). They generally agreed that their workdays varied "daily in pace due to unforeseen circumstances" (mean = 7.06); however, there were no significant differences by department (Q10c). Responses to two statements showed significance by department (Q10a-b). Professionals were in slight agreement that their work duties were "flexible and on my own timeline" (mean $=6.39)$, with assessment $(+2.86,4)$ and collection development $(+1.51,11)$ at the top of the scale and interlibrary loan $(-1.52,4)$ in least agreement. They were in similar agreement that their duties consisted "of fits and starts through the day" (mean $=6.20)$, with web services $(+1.30,6)$ at the top of the scale and communication or special events $(-1.87,3)$ in least agreement.

Respondents were consistent in agreeing or strongly agreeing that they meet deadlines (282 of 320). There was general disagreement $($ mean $=2.17,321)$ to the statement that time was not an important aspect of completing a task (Q11c). Interlibrary loan $(-1.17,4)$ and acquisi- 
tions $(-.50,7)$ were the most affected by time, while binding or preservation $(+.83,2)$ and digital initiatives $(+.64,16)$ were least affected. The average response to "I generally feel very rushed at work" (Q11a), was disagreement (mean = 2.83, 320); however, departments differed, with web services $(+.73,6)$ and administration $(+.38,43)$ agreeing more greatly that they felt rushed. Assessment $(-1.08,4)$ and systems or information technology $(-.68,17)$ were less rushed.

Most librarians were in agreement that they look for ways to work more efficiently (Q9j, mean $=4.20)$ and that they use technologies to that end $(Q 9 d$, mean $=3.94)$. They were in much less agreement with regard to the multitasking that often is caused by those technologies. In regard to the statement "multitasking energizes me" $(\mathrm{Q} 9 \mathrm{~b})$, both departmental affiliation $(p$ $=.013)$ and years in the profession were significant to a professional's view $(p=.018)$. While many respondents (90 of 321) neither agreed nor disagreed with the energizing effect of multitasking $($ mean $=3.03,321)$, serials $(+.97,4)$ and communication or special events personnel $(+.97,3)$ responded that they were more energized. Web services $(-.36,6)$ and cataloging or metadata $(-.24,24)$ most disagreed with the statement. In addition, for this question the years in the profession was also significant $(p=.018$, mean $=3.03)$, with both the longest employed, more than 30 years $(+.23,47)$, and the newest employees, $1-5$ years $(+.19,76)$, agreeing the most.

\begin{tabular}{|c|c|c|c|c|}
\hline \multicolumn{5}{|c|}{$\begin{array}{c}\text { TABLE } 2 \\
\text { Departments Perceived as the Most and Least Governed by Deadlines }\end{array}$} \\
\hline \multirow[t]{2}{*}{ Department } & \multicolumn{2}{|c|}{ Most } & \multicolumn{2}{|c|}{ Least } \\
\hline & Rank & Number & Rank & Number \\
\hline Access Services or Circulation & 3 & 28 & 9 & 14 \\
\hline Acquisitions & 1 & 55 & 19 & 2 \\
\hline Assessment & 16 & 2 & 14 & 5 \\
\hline Audio or Media & 18 & 1 & 16 & 4 \\
\hline Binding or Preservation & 20 & 0 & 3 & 28 \\
\hline Cataloging or Metadata & 16 & 2 & 2 & 47 \\
\hline Collection Development & 9 & 17 & 9 & 12 \\
\hline Communication or Special Events & 8 & 18 & 14 & 5 \\
\hline Digital Initiatives & 12 & 8 & 7 & 15 \\
\hline Government Documents & 20 & 0 & 6 & 17 \\
\hline Human Resources & 6 & 19 & 17 & 3 \\
\hline Instruction & 3 & 28 & 17 & 3 \\
\hline Interlibrary Loan & 2 & 52 & 20 & 1 \\
\hline Public Services & 6 & 19 & 10 & 12 \\
\hline Reference & 9 & 11 & 5 & 21 \\
\hline Serials & 14 & 3 & 20 & 1 \\
\hline Special Collections or Archives & 18 & 1 & 1 & 61 \\
\hline Systems or Information Technology & 5 & 20 & 10 & 12 \\
\hline Technical Services & 13 & 5 & 10 & 12 \\
\hline Web Services & 14 & 3 & 13 & 9 \\
\hline Other & 11 & 16 & 7 & 15 \\
\hline No Answer & 9 & 17 & 4 & 26 \\
\hline Total & & 325 & & 325 \\
\hline
\end{tabular}


The final questions of the survey focused on the perception of departments most and least governed by deadlines. Results are given in table 2 .

These data show a consistent perception: both acquisitions and interlibrary loan received by far the greatest number of responses for most governed and the fewest number for least governed. Respondents clearly viewed these two departments as driven by deadlines. On the opposite side of the spectrum, special collections or archives and cataloging or metadata received by far the highest number of responses for least governed by deadlines and fewest for most governed. The chart also shows considerable spread between the top two and thirdhighest response in each question. On the whole, the data indicate that respondents felt that deadlines have a disproportionate impact on several departments.

\section{Discussion}

The data present an intriguing view of sociotemporal culture within a sample of academic librarians and yield several surprising results. The results show a significantly stronger relationship between a librarian's department and sociotemporal orientation than sociotemporal orientation and the individual's age, gender, or seniority. Within a professional literature that extensively covers cross-functional interdepartmental teams and putative differences across generations and genders, this finding may be unexpected. However, whereas traditional and emerging departments show a distinct sociotemporality, departments that have traditionally resided together in larger organizational groupings showed dissimilarities. As an example, considerable data from respondents reporting cataloging or metadata as their department diverged from data from respondents reporting acquisitions. In short, department is an indicator of sociotemporal attributes, whereas "division" is not. On a similar note, as reported above, respondents across departments ranked acquisitions as heavily driven by deadlines and cataloging or metadata at the opposite pole. These sociotemporal differences within academic libraries in the United States are less clear-cut than the disparities that separated doctors and nurses in Zerubavel's study of the hospital, but they are compelling nonetheless.

Limitations of this study should not be overlooked. First, the findings cannot be generalized across librarianship in the United States, although responses represented a fair crosssection of the United States. Second, distributing the survey through the dean or director of each academic library most likely led to a disproportionate number of responses from administrators and tilted the responses with the departmental affiliation Administration toward the chief administrator. Finally, it is essential to note that the data depict self-reported attitudes and behavior-not observed behavior. For example, it is possible that some respondents reported that they consistently heed deadlines but fail to meet them.

These limitations do not undercut the practical matters that the data raise for administrators and other managers. Organizations should accommodate varying approaches to work, much as they welcome diverse perspectives, but they must decide to what degree they should accommodate outliers. Individuals who regularly fail to meet deadlines or feel that a communal activity should not impinge upon their afternoon break push the boundaries of a reasonable accommodation and may undermine the workplace. Ultimately managers in academic libraries must enforce a reasonable standard of work - as do managers in any environment. ${ }^{45}$ This article does not provide answers to questions raised by disparate approaches to time, schedules, and other temporal matters in academic libraries, but the research can raise awareness and help frame the conversations. Research of sociotemporal 
culture can identify how it is integral to the larger organizational culture and remind scholars and practitioners that time should never be assumed and is a valuable category of analysis.

The data also raise a thought-provoking question best viewed through the metaphor of the chicken or the egg: Do professional personnel in academic libraries with a particular orientation toward time gravitate toward specific types of work or departments? Or does the appointment of an individual into a department, with its particular sociotemporal culture, shape the employee? Or could it be a combination of the two? This riddle is beyond the scope of this paper but could be a point of future research. Another intriguing point, and a further segue to recommendations for future research: the sociotemporal orientations of departments may have value in rethinking traditional groupings of functions or departments on organizational charts. To be more specific, the conceptions of time that acquisitions and interlibrary loan share, including the shared emphasis on deadlines, may suggest an organizational pairing that has rarely appeared in the literature. ${ }^{46}$

\section{Recommendations for Future Research}

The authors encountered several challenges in the project that could be relevant to future studies. First was length: a shorter instrument could have prompted a higher response rate. Second, although the distribution of the survey through the dean or director was intended to ensure that only the intended subjects (librarians and feral professionals) took the survey and that the chief administrator encouraged participation, it was apparent that some administrators had distributed the invitation more broadly. Because only half the institutions were represented in the results, the flipside was a problem as well. Some administrators chose not to distribute the survey, with a few citing "survey fatigue" as their objection. Several other institutions did not respond to the authors' subsequent requests to forward the invitation. If the authors were to repeat the study, they would disseminate the request broadly in hopes of obtaining more responses, rather than selectively through an intermediary.

The literature review indicated that perceptions of time within a workplace are evident in the subcultures within the workplace. It could be appropriate in future inquiries to pursue other methods for identifying the subcultures in academic libraries. The authors used traditional departmental and divisional titles to create the parameters of these subcultures. Minimal data cleanup was necessary: almost all participants selected a department, and these affiliations proved significant. It may be argued that, as libraries have changed, the use of traditional departments may no longer be the ideal basis for understanding library subcultures. Although this article found significance in these organizational units as variables, similar studies could present a more nuanced picture by focusing on functional duties in lieu of formal organization structures. A subsequent study also could broaden the inquiry beyond the United States to add an international perspective.

As this study analyzed self-reported behaviors and perceptions, some demographic dissimilarities may have been overlooked. Research into observed behavior could provide greater insight. And although this article explored the operation of sociotemporality rather than the causes of sociotemporal differences, future researchers may enrich the literature of librarianship by pinpointing these causes through a careful unpacking of the intertwined aspects of employees' personal and professional lives.

As academic librarians, the authors are primarily interested in the academic library. An examination and comparison of temporal issues in larger public libraries, whose organiza- 
tional structures often resemble those of academic libraries, could be illustrative. The degree to which departmental affiliation determines one's sociotemporal orientation across the two major types of libraries could further illuminate the role of departmental "citizenship," as well as similarities and dissimilarities between academic and public libraries.

\section{Conclusion}

Omnipresent and yet oft hidden, time is an important element in the rhythm and organizational life of academic libraries. A considerable body of literature outside librarianship has explored the sociology of time in a variety of workplaces to show how employees' experiences of time, as well as urgency, calendars, and seasons, diverge. This article extends the investigation to the academic library. This research found that departmental affiliation was the most important determination in librarians' conception and experience of time and that standard demographic categories of gender, age, and seniority were not significant predictors of sociotemporal differences. In short, the immediate group in which an academic librarian works may share a temporal culture. This inquiry into the sociology of time in academic libraries begins a conversation that could prompt a more critical appreciation of time-and its effects among diverse groups of workers - as academic librarians build effective organizations that serve the research, teaching, and service of the colleges and universities of the present and future.

\section{Acknowledgments}

The authors express their appreciation for colleagues who completed the survey. They also recognize the editor and anonymous reviewers whose insightful criticism of the manuscript strengthened the published work. 


\section{APPENDIX. Survey Questions}

Q1 In what department do you work? Please select the name that is most closely associated. If you are employed in an administrative position (in other words, a managerial position above a department head), please select Administration.

Q1b If other, please describe.

Q2 How many years have you worked in a professional position in a library? This includes librarian and nonlibrarian salaried positions.

․ 1-5 years

6-10 years

11-15 years

ㅁ 16-20 years

21-30 years

$\square \quad>30$ years

Q3 What is your gender?

$\square$ Male

Female

Q4 What is your age?

25-34

35-44

45-54

55-64

$65-74$

Q5 What is the level of education you have completed? Check all that apply.

2-year college degree

$\square \quad$ 4-year college degree

- Master's degree in Library and/or Information Science

$\square \quad$ Master's degree in other discipline

$\square$ Doctoral degree in Library and/or Information Science

$\square$ Doctoral degree in other discipline

$\square$ Other graduate degree or certificate

口 Other:

Q6 Are you the sole person in your household?

$\square$ Yes

$\square$ No

Q7 What is your annual income?

$\square$ under $\$ 39,999$

ㄴ $\$ 40,000-\$ 59,999$

ㄴ $\$ 60,000-\$ 79,999$

\$80,000-\$99,999

$\$ 100,000-\$ 119,999$

- \$120,000 and over

$\square \quad$ Prefer not to disclose

Q8 Who do you feel are your primary clientele?

[Open Ended] 
Q9 Please select the response that best represents your general perceptions.

\begin{tabular}{|c|c|c|c|c|c|}
\hline & $\begin{array}{l}\text { Strongly } \\
\text { Disagree }\end{array}$ & Disagree & $\begin{array}{l}\text { Neither } \\
\text { Agree nor } \\
\text { Disagree }\end{array}$ & Agree & $\begin{array}{l}\text { Strongly } \\
\text { Agree }\end{array}$ \\
\hline $\begin{array}{l}\text { a. I consider myself to be most productive in the } \\
\text { evening }\end{array}$ & & & & & \\
\hline b. Multitasking energizes me & & & & & \\
\hline $\begin{array}{l}\text { c. I find it more difficult to complete ongoing } \\
\text { tasks without a deadline than tasks with a clear } \\
\text { deadline }\end{array}$ & & & & & \\
\hline $\begin{array}{l}\text { d. Technologies such as email and texting enable } \\
\text { me to work more efficiently }\end{array}$ & & & & & \\
\hline $\begin{array}{l}\text { e. I would rather come early and wait than be } \\
\text { late for an appointment }\end{array}$ & & & & & \\
\hline f. I work better without interruptions & & & & & \\
\hline g. I tend to procrastinate & & & & & \\
\hline $\begin{array}{l}\text { h. I consider myself most productive early in the } \\
\text { morning }\end{array}$ & & & & & \\
\hline $\begin{array}{l}\text { i. I am almost never late for work or } \\
\text { appointments }\end{array}$ & & & & & \\
\hline j. I look for ways to work more efficiently & & & & & \\
\hline
\end{tabular}

Q10 On a scale of $0-10$, where 0 indicates never and 10 indicates very frequently, my work duties on the whole can be described as:

a. Consisting of fits and starts through the day

b. Flexible and on my own timeline

c. Varies daily in pace due to unforeseen circumstances

Q11 Please select the most fitting response.

\begin{tabular}{|l|l|l|l|l|l|}
\hline & $\begin{array}{l}\text { Strongly } \\
\text { Disagree }\end{array}$ & Disagree & $\begin{array}{l}\text { Neither } \\
\text { Agree nor } \\
\text { Disagree }\end{array}$ & Agree & $\begin{array}{l}\text { Strongly } \\
\text { Agree }\end{array}$ \\
\hline a. I generally feel very rushed at work & & & & & \\
\hline b. I almost always meet deadlines & & & & & \\
\hline $\begin{array}{l}\text { c. Time is not an important aspect in } \\
\text { completing my tasks }\end{array}$ & & & & \\
\hline
\end{tabular}

Q12 My work duties are affected by:

\begin{tabular}{|l|l|l|l|}
\hline & Not Applicable & Occasionally & Frequently \\
\hline $\begin{array}{l}\text { a. My own deadlines } \\
\text { beadlines determined by library }\end{array}$ & & & \\
\hline $\begin{array}{l}\text { c. Deadlines determined by my immediate } \\
\text { supervisor }\end{array}$ & & & \\
\hline
\end{tabular}




\begin{tabular}{|l|l|l|l|}
\hline $\begin{array}{l}\text { d. Expectations by other persons within my } \\
\text { department }\end{array}$ & & & \\
\hline $\begin{array}{l}\text { e. Expectations from other departments in } \\
\text { the library }\end{array}$ & & & \\
\hline $\begin{array}{l}\text { f. Expectations by student and faculty } \\
\text { clientele }\end{array}$ & & & \\
\hline g. The campus calendar & & & \\
\hline h. External vendors and businesses & & & \\
\hline i. Other entities & & & \\
\hline
\end{tabular}

Q13 My work responsibilities make it challenging to schedule my vacation.

$\square \quad$ Not at all

$\square$ Occasionally

$\square \quad$ Frequently

Q14 My work responsibilities require me to be "connected" during my vacation.

$\square \quad$ Not at all

$\square$ Occasionally

$\square$ Frequently

Q15 I am very conscious of the academic calendar and its implications on my work.

$\square \quad$ Not at all

$\square$ Occasionally

$\square$ Frequently

Q16 What is the most stressful month of the work year?

[Open ended]

Q17 What time considerations define your most stressful month?

[Open ended]

Q18 My work has a seasonal aspect to it.

$\square$ Yes

$\square \quad$ No

Q19 Please select the response that best reflects your personal approach to time.

\begin{tabular}{|l|l|l|l|l|l|}
\hline & $\begin{array}{l}\text { Strongly } \\
\text { Disagree }\end{array}$ & Disagree & $\begin{array}{l}\text { Neither } \\
\text { Agree nor } \\
\text { Disagree }\end{array}$ & Agree & $\begin{array}{l}\text { Strongly } \\
\text { Agree }\end{array}$ \\
\hline $\begin{array}{l}\text { a. I should alter my schedule to accommodate } \\
\text { my colleagues' professional duties }\end{array}$ & & & & \\
\hline b. I like to have a definite schedule and stick to it & & & & & \\
\hline c. I often take work home at the end of the day & & & & & \\
\hline $\begin{array}{l}\text { d. I should alter my schedule to accommodate } \\
\text { the library's clientele }\end{array}$ & & & & & \\
\hline e. I like to eat lunch at the same time of the day & & & & & \\
\hline $\begin{array}{l}\text { f. I tend to arrive at and leave work at the same } \\
\text { times each day }\end{array}$ & & & & & \\
\hline $\begin{array}{l}\text { g. I make myself available to the library when I } \\
\text { am not at work }\end{array}$ & & & & & \\
\hline
\end{tabular}




\begin{tabular}{|l|l|l|l|l|l|}
\hline h. I avoid working on weekends & & & & & \\
\hline i. I regularly work at home in lieu of the office & & & & & \\
\hline j. I take regular breaks at work & & & & & \\
\hline
\end{tabular}

For the following questions, other than your library administration...

Q20 What department or unit of your library appears to be the most governed by deadlines?

$\nabla$ Select a department

Q21 What department or unit of your library (other than your own) most determines your deadlines?

$\boldsymbol{\nabla}$ Select a department

Q22 What department or unit of your library appears to be the least governed by deadlines? $\nabla$ Select a department

Q23 What department or unit of your library has the greatest expectation of a quick turnaround for your work?

$\nabla$ Select a department

Q24 What department or unit of your library has the greatest expectation of a quick turnaround for work in general?

$\nabla$ Select a department

Q25 Deadlines for my work conflict with the expectations of other library departments or units.

$\square \quad$ Never

$\square$ Occasionally

$\square$ Very Often

$\square$ Always

Q26 Please select the option that is the most fitting response.

\begin{tabular}{|l|l|l|l|l|l|}
\hline & $\begin{array}{l}\text { Strongly } \\
\text { Disagree }\end{array}$ & Disagree & $\begin{array}{l}\text { Neither } \\
\text { Agree nor } \\
\text { Disagree }\end{array}$ & Agree & $\begin{array}{l}\text { Strongly } \\
\text { Agree }\end{array}$ \\
\hline $\begin{array}{l}\text { a. Attending campus activities outside of my } \\
\text { regular schedule is an important aspect of } \\
\text { membership in academe }\end{array}$ & & & & & \\
\hline $\begin{array}{l}\text { b. Deadlines are important for the smooth } \\
\text { running of an academic library }\end{array}$ & & & & & \\
\hline $\begin{array}{l}\text { c. I am optimistic about the future of academic } \\
\text { libraries }\end{array}$ & & & & & \\
\hline
\end{tabular}




\section{Notes}

1. It should be noted that the 40-hour Monday to Friday workweek is not universal, although many countries had legislated a standard of 40 hours by the mid-1980s. For an in-depth study of global work patterns and discrepancies between legal standards and actual hours worked, see Sangheon Lee, Deirdre McCann, and Jon C. Messenger, Working Time around the World: Trends in Working Hours, Laws and Policies in a Global Comparative Perspective (New York, NY: Routledge, 2007).

2. For a recent survey of the historical literature on temporalities, see Matthew S. Champion, "The History of Temporalities: An Introduction," Past and Present, no. 243 (May 2019): 247-54, https://doi.org/10.1093/pastj/gtz007. Champion's essay frames five other articles in the issue. See also notes 4 and 6-8 below.

3. Eviatar Zerubavel, Patterns of Time in Hospital Life: A Sociological Perspective (Chicago, IL: University of Chicago Press, 1979), 105.

4. Matthew S. Champion, "A Fuller History of Temporalities," Past and Present, no. 243 (May 2019): 256, https:// doi.org/10.1093/pastj/gtz008.

5. Champion, "The History of Temporalities," 248-49.

6. E.P. Thompson, "Time, Work-Discipline, and Industrial Capitalism," Past and Present, no. 38 (December 1967): 56-97, https://www.jstor.org/stable/649749. For a fresh appraisal of Thompson's thesis, see Vanessa Ogle, “Time, Temporality and the History of Capitalism," Past and Present, no. 243 (May 2019): 312-27, https://doi. org/10.1093/pastj/gtz014.

7. Thompson, "Time, Work-Discipline, and Industrial Capitalism," 86, 89, 95.

8. Thompson, "Time, Work-Discipline, and Industrial Capitalism," 63-70.

9. The authors found 1,580 cited references in Web of Science to Thompson's article. Web of Science, https:// clarivate.com/webofsciencegroup/solutions/web-of-science/ [accessed August 22, 2019].

10. Zerubavel, Patterns of Time in Hospital Life, xi.

11. Zerubavel, Patterns of Time in Hospital Life, 105.

12. Eviatar Zerubavel, Hidden Rhythms: Schedules and Calendars in Social Life (Chicago, IL: University of Chicago Press, 1981).

13. Christena E. Nippert-Eng, Home and Work: Negotiating Boundaries through Everyday Life (Chicago, IL: University of Chicago Press, 1996).

14. Christine Everingham, "Engendering Time: Gender Equity and Discourses of Workplace Flexibility," Time \& Society 11, no. 2/3 (2002): 335-51, https://doi.org/10.1177/0961463X02011002009.

15. S.D. Quan et al., "Perceptions of Urgency: Defining the Gap between What Physicians and Nurses Perceive to Be an Urgent Issue," International Journal of Medical Informatics 82, no. 5 (2013): 378-86.

16. Quan et al., "Perceptions of Urgency," 383.

17. Quan et al., "Perceptions of Urgency," 383.

18. John Hassard, "Aspects of Time in Organization," Human Relations 44, no. 2 (1991): 105-25.

19. Hassard, "Aspects of Time in Organization," 123.

20. Bernhard Albert, "Temporal Diversity': A Note on the 9th Tutzing Time Ecology Conference," Time $\mathcal{E}$ Society 11, no. 1 (2002): 95.

21. Albert, "Temporal Diversity," 99.

22. Mary J. Waller et al., "The Effect of Individual Perceptions of Deadlines on Team Performance," Academy of Management Review 26, no. 4 (2001): 586-600.

23. Dawna I. Ballard and David R. Seibold, "Time Orientation and Temporal Variation across Work Groups: Implications for Group and Organizational Communication," Western Journal of Communication 64, no. 2 (2000): 240.

24. Susan Mohammed and Sucheta Nadkarni, "Temporal Diversity and Team Performance: The Moderating Role of Team Temporal Leadership," Academy of Management Journal 54, no. 3 (2011): 489-508.

25. Susan Mohammed and David A. Harrison, "The Clocks That Time Us Are Not the Same: A Theory of Temporal Diversity, Task Characteristics, and Performance in Teams," Organizational Behavior and Human Decision Processes 122, no. 2 (2013): 244-56.

26. Jacquelyn B. Schriber and Barbara A. Gutek, "Some Time Dimensions of Work: Measurement of an Underlying Aspect of Organizational Culture," Journal of Applied Psychology 72, no. 4 (1987): 642.

27. Jonathon R.B. Halbesleben et al., "Awareness of Temporal Complexity in Leadership of Creativity and Innovation: A Competency-Based Model," Leadership Quarterly 14, no. 4/5 (2003): 433, https://doi.org/10.1016/ S1048-9843(03)00046-8.

28. Svein Kyvik, "Academic Workload and Working Time: Retrospective Perceptions Versus Time-Series Data," Higher Education Quarterly 67, no. 1 (2013): 2-14. 
29. Kyvik, "Academic Workload and Working Time," 7-8.

30. Edvard Konrad and Mihael Kline, "Time in Organizations: A Preliminary Study in Time Urgency," Psychologische Beiträge 32, no. 1/2 (1990): 26.

31. Konrad and Kline, "Time in Organizations," 27.

32. Diane Mizrachi and Marcia J. Bates, "Undergraduates' Personal Academic Information Management and the Consideration of Time and Task-Urgency," Journal of the American Society for Information Science and Technology 64, no. 8 (2013): 1590-1607.

33. Thomas D. Meyers and Alice W. Sewell, "Socialization Experiences and Time Attitudes of Young Adults," Sociological Viewpoints 13 (1997): 21-23.

34. Meyers and Sewell, "Socialization Experiences and Time Attitudes of Young Adults," 26.

35. Jerald Greenberg, "Time Urgency and Job Performance: Field Evidence of an Interactionist Perspective," Journal of Applied Social Psychology 32, no. 9 (2002): 1964-73.

36. Goodluck Israel Ifijeh, “Time Management Strategies for Improving Librarians' Productivity," Bilgi Dünyasi 13, no. 2 (2012): 565-73, http://bd.org.tr/index.php/bd/article/view/86 [accessed August 22, 2019].

37. Rick Anderson, "IMHBCO (In My Humble but Correct Opinion)," Against the Grain 26, no. 5 (2014): 78-79, https://doi.org/10.7771/2380-176X.6850.

38. Anderson, "IMHBCO (In My Humble but Correct Opinion)," 79.

39. Dana M. Miller and Teressa Keenan, "The Time Management Study as a Tool for New Technical Services Managers," Library Leadership \& Management 30, no. 1 (2015): 1-22.

40. Neal has addressed this concept on multiple occasions. For an early reference, see James G. Neal, "Raised by Wolves: Integrating the New Generation of Feral Professionals into the Academic Library," Library Journal 131, no. 3 (2006): 42-44.

41. "Table B-5: Number of Higher Education Credentialed Librarians by Characteristic, 2000," American Library Association Diversity Counts 2009-2010 Update, www.ala.org/aboutala/sites/ala.org.aboutala/files/ content/diversity/diversitycounts/diversitycountstables2012.pdf [accessed August 26, 2019].

42. "Table A-1: Number of Credentialed Librarians by Characteristic, 2009-2010," American Library Association Diversity Counts 2009-2010 Update, www.ala.org/aboutala/sites/ala.org.aboutala/files/content/diversity/ diversitycounts/diversitycountstables2012.pdf [accessed August 26, 2019].

43. "Table 11: Employed Persons by Detailed Occupation, Sex, Race, and Hispanic or Latino Ethnicity (2017)," Current Population Survey, https://www.bls.gov/cps/cpsaat11.pdf [accessed August 26, 2019]; and "Diversity: Gender Composition," Data USA: Librarians, https://datausa.io/profile/soc/254021/\#demographics [accessed August 26, 2019].

44. For examples, see Cassidy R. Sugimoto et al., "Beyond Gatekeepers of Knowledge: Scholarly Communication Practices of Academic Librarians and Archivists at ARL Institutions," College E Research Libraries 75, no. 2 (2014): 149, https://doi.org/10.5860/crl12-398; Amanda L. Folk, "Academic Reference and Instruction Librarians and Dweck's Theories of Intelligence," College E Research Libraries 77, no. 3 (2016): 308, https://doi.org/10.5860/ crl12-398; and Leo S. Lo and Bethany Herman, "An Investigation of Factors Impacting the Wellness of Academic Library Employees," College E Research Libraries 78, no. 6 (2017): 793-94, https://doi.org/10.5860/crl.78.6.789.

45. For a detailed analysis of this point and quotation by a library administrator, see Kara J. Malefant, "Leading Change in the System of Scholarly Communication: A Case Study of Engaging Liaison Librarians for Outreach to Faculty," College \& Research Libraries 71, no. 1 (2010): 72.

46. For a rare example, see Joe Badics, "Acquisitions and Interlibrary Loan Together: Good Marriage or Will George W. Bush Object?" Against the Grain 16, no. 4 (2004): 52, 54. For a contrasting perspective, see Hong Ta-Moore and Kathleen S. Mannino, "A Case for Integration of Interlibrary Loan and Reference," Journal of Interlibrary Loan, Document Delivery E Electronic Reserve 22, no. 5 (2012): 197-203, https://doi.org/10.1080/1072303X.2012.723672. 